\title{
PRIVACIDADE EM TEMPOS DE INTERNET: COMPORTAMENTO E DISCURSIVIZAÇÃO DE SI ENTRE USUÁRIOS NO AMBIENTE VIRTUAL
}

\author{
PRIVACY IN INTERNET TIMES:
}

BEHAVIOR AND SELF-TALK BETWEEN USERS IN THE VIRTUAL ENVIRONMENT

\author{
Fausi dos SANTOS ${ }^{1}$ \\ Paulo Rennes Marçal RIBEIRO ${ }^{2}$
}

RESUMO: O artigo apresenta as transformações produzidas no comportamento dos usuários da internet com o advento do Mundo Virtual, principalmente na exteriorização da privacidade e intimidade em redes sociais. É comum entre muitos internautas a discursivização de seus afazeres diários, bem como, a manifestação de seus desejos e fantasias pessoais no ambiente virtual, em muitos casos na busca de aceitação e reconhecimento por outros usuários. Tal comportamento leva a uma produção subjetiva da personalidade, que se transforma em perfil nas redes sociais, fazendo circular múltiplos efeitos de sentido que são produzidos por diferentes usuários que comentam, curtem e compartilham tais publicações.

PALAVRAS-CHAVE: Privacidade. Redes sociais. Subjetividade. Discurso.

ABSTRACT: The article presents the transformations produced in the behavior of Internet users with the advent of the Virtual World, mainly in the exteriorization of privacy and intimacy in social networks. It is common among many netizens to discurse their daily activities, as well as the manifestation of their personal desires and fantasies in the virtual environment, in many cases in the search for acceptance and recognition by other users. Such behavior leads to a subjective production of personality, which becomes a profile in social networks, circulating multiple effects of meaning that are produced by different users who comment, enjoy and share such publications.

KEYWORDS: Privacy. Social networks. Subjectivity. Speech.

Em tempos de internet não é novidade para uma grande parcela da humanidade ${ }^{3}$ a

\footnotetext{
${ }^{1}$ Universidade Estadual Paulista (Unesp), Faculdade de Ciências e Letras, Araraquara - SP - Brasil. Doutorando no Programa de Educação Escolar com ênfase em Educação Sexual. E-mail: fausifilo@ @otmail.com.

${ }^{2}$ Universidade Estadual Paulista (Unesp), Faculdade de Ciências e Letras, Araraquara - SP - Brasil. Professor Adjunto no Departamento de Psicologia da Educação e Coordenador do Programa de Pós-Graduação em Educação Sexual. E-mail: paulorennes@fclar.unesp.br .

${ }^{3}$ É latente aqui a ideia da exclusão digital que acomete grande parte da humanidade, seja pela desigualdade social que ocasiona o não acesso ao computador e internet ou ainda as péssimas situações educacionais que provocam o analfabetismo digital. De uma forma ou outra existem sociedades que ainda lutam pela sobrevivência diária, seja contra a fome, guerras ou ideologias políticas que distanciam os indivíduos das tecnologias digitais.
} 
experiência diária na troca de arquivos online. O aperfeiçoamento de aplicativos vem otimizando o envio e recebimento de fotos, vídeos, imagens, textos e uma infinidade de materiais diversos que em tempo real alcançam pessoas conectadas em qualquer parte do planeta. A digitalização da informação e o rápido acesso de dados facilitaram de forma sensível o trabalho e o desempenho de variadas instituições privadas ou públicas em todas as sociedades, uma vez que a apropriação da informação aperfeiçoou processos, agilizou a comunicação e interligou diferentes agentes sociais como empresas, governos, forças públicas de segurança, sistemas educacionais e outras tantas demandas. Portanto, a internet se processa como uma revolução não somente das relações interpessoais, mas também como uma revolução das instituições supra pessoais.

Concernente às relações interpessoais, o contato de uma parcela de usuários com os computadores e a internet tem provocado uma sintomática e crescente exteriorização da vida privada com o espaço público. Experiências íntimas com suas expressões próprias sejam elas fatos cotidianos, demandas afetivas ou sexuais são externadas e discursivizadas abertamente em redes sociais. Tal fenômeno se evidencia desde a troca de mensagens com posicionamentos ideológicos, políticos, banalidades pessoais até o uso destes aplicativos para obtenção de prazer afetivo ou sexual, seja na troca de fotos e vídeos pessoais com conteúdo erótico ou pornográfico, os chamados nudes, até a conversação romântica ou erotizada.

Tornou-se corriqueiro encontrar pessoas conectadas 24 horas por dia que dividem seu tempo de trabalho ou de estudos com chats de bate papo, blogs, twiter, facebook, instagran e uma infinidade de outras redes sociais. Maquinarias que o colocam em contato com dezenas de amigos virtuais, onde trocam intimidades, postando acontecimentos, compartilhando pensamentos e imagens e em alguns casos lendo e escrevendo aforismos sobre política, literatura e uma infinidade de futilidades diárias.

A respeito das relações de afeto nas redes sociais, Bauman (2004, p. 52) afirma,

[...] nós entramos nos chats e temos 'camaradas' que conversam conosco. Os camaradas, como bem sabe todo viciado em chat, vêm e vão, entram e saem do circuito - mas sempre há na linha alguns deles se coçando para inundar o silêncio com 'mensagens'. No relacionamento 'camarada/camarada', não são as mensagens em si, mas seu ir e vir, sua circulação, que constitui a mensagem - não importa o conteúdo. Nós pertencemos ao fluxo constante de palavras e sentenças inconclusas (abreviadas, truncadas para acelerar a circulação). Pertencemos à conversa, não àquilo sobre o que se conversa.

A desterritorialização provocada pela virtualização das relações quebra a noção de tempo e espaço, aproxima pessoas que muitas vezes se encontram a quilômetros de distância, 
cria uma inversão no conceito do aqui e agora, na medida em que traz para a ponta dos dedos uma cadeia de possibilidades, de mecanismos que estimulam as fantasias e desejos e abrem a possibilidade para a maior exposição da pessoa.

Raras vezes na história o corpo foi tão exposto como na atualidade pelas redes sociais. O que antes ficava privado a um álbum de família guardado a sete chaves, hoje é disponibilizado em fotoblogs, facebook, instagram, álbuns virtuais de todos os gêneros. Não é difícil se deparar com perfis abertos onde meninos e meninas se exibem em fotografias em variadas situações. Sejam em eventos públicos ou na intimidade do quarto, em poses sensuais, às vezes demonstrando atributos de beleza, força, virilidade, ou de posicionamentos ideológicos (político, esportivo, étnico etc).

As redes sociais se tornaram um sistema maquínico onde o corpo e as expressões de afeto são veiculadas ao espaço público mundial. É a plataforma no qual a subjetividade, os corpos e a sexualidade são expostos de forma cada vez mais comum, não utilizando critérios de produção e postagem, sendo uma ferramenta apenas para expressão das vontades e desejos pessoais, uma via de expressão das fantasias, uma válvula de um querer e desejar anárquica quase sempre.

Outro aspecto que as redes sociais evidenciam é a fuga do indivíduo das adversidades e descontentamentos da vida real para o mundo virtual. Não é raro encontrar pessoas que substituem o convívio familiar, provocam o afrouxamento das relações sociais e em muitos casos na diluição de relacionamentos amorosos (casamentos e namoros) para "viver um romance virtual". Em alguns casos há até a substituição do sexo real pelo sexo virtual, veiculados por esses indivíduos a um grau de satisfação e realização superiores ao sexo real.

É óbvio que na maioria dos casos se constata um deslocamento na percepção que esses indivíduos possuem sobre si mesmos e seus corpos. Em muitos casos a vida amorosa, sexual e social de alguns usuários é marcada pela rejeição, seja por padrões de comportamento e vícios de personalidade ou deformidades físicas e limites orgânicos que a impedem de possuir uma vida sexual prazerosa. A internet, nestes casos, se torna uma prótese que potencializa e projeta aquilo que os limites do corpo não podem alcançar. Há também casos de degeneração das relações amorosas, o que pode levar a casos de "traição virtual" e toda espécie de comportamento que converte as maquinarias computacionais em plataformas da expressão das pulsões sexuais e dos afetos.

De qualquer forma a internet tornou se o espaço da manifestação dos desejos que denuncia um tipo específico de subjetividade: é o espaço da conversação, da troca de ideias, da veiculação das futilidades, da sondagem da vida das personalidades, da expressão de 
desejos, dos afetos, da canalização das carências e frustrações, da construção de subjetividades sobre subjetividades por meio de personagens imagéticos, sejam perfis ou avatares (imaginário ou virtual), fruto da livre criação dos afetos.

O mundo virtual é um espaço rizomático, na medida em que possui várias entradas e saídas, que dá ao usuário infinitas possibilidades de se conectar ao circuito de participação. Por isso mesmo é volúvel e efêmero como os próprios laços humanos que comunga de uma tendência fluida que perpassa a personalidade e os afetos dos indivíduos no meio social. Da mesma forma que o usuário da rede pode se conectar e desconectar quando melhor desejar, as relações de afeto e sexualidade também são marcadas por essa característica interativa e rápida.

\section{Sobre subjetivação e a noção de sujeito nas redes sociais e nos sites de relacionamento.}

Se comparado à noção de unidade ou identidade do passado o sujeito na pósmodernidade possui características de fragmentação de sua personalidade pessoal e social. Illouz mostra, por exemplo, que a internet permite um eu muito mais flexível, aberto e múltiplo, um eu inventor de si mesmo e até enganoso, que se reinventa ao bel prazer das necessidades que mudam a cada momento, seguindo a dinâmica dos bens simbólicos construídos pelo mercado.

Afirma Illouz (2011, p. 115) que,

[...] o trabalho de apresentação pessoal encenado na e através da internet consiste exclusivamente na linguagem - e, mais especificamente, na linguagem escrita - e porque não é orientado para um indivíduo concreto e específico, mas para um público geral de candidatos abstratos e desconhecidos. Em outras palavras, o trabalho de apresentação pessoal do eu pós-moderno pressupõe e implica a capacidade de ser sensível a diferentes contextos sociais e de neles encenar papéis diferentes.

A apresentação pessoal do eu discutida por Illouz (2011) nas redes digitais usa a linguagem como um meio para reconstruir diferentes modalidades de subjetividade. Ao montar discursivamente múltiplas faces como um caleidoscópio de "eus", produz e destrói perenemente subjetividades, sendo as plataformas computacionais e informacionais convertidas em "técnicas de si"4. Tais subjetividades têm emergência e sentido de ser, devem

${ }^{4}$ O conceito "técnicas de si" pertencente a Michel Foucault (1998), trata das práticas individuais utilizadas para dar forma e significado a um determinado tipo de produção, seja ela um produto simbólico ou material. Essas técnicas se dividem em quatro grandes grupos, onde cada qual representa uma matriz da razão prática: 1) as 
ser acessadas em diferentes situações e realidades, pois pertencem a um cenário líquido e fugaz que muda constantemente com um público tão plural e geral, indivíduos tão abstratos e desconhecidos que exigem um "eu" volátil que se encaixe a cada situação como uma peça num quebra cabeça.

A fragmentação do sujeito é acompanhada por uma polissemia linguística, dada pela necessidade de criar modos infinitos de dizer e de reconstruir discursos. Há emergência em demonstrar e discutir a avalanche de informações produzidas e disseminadas pelas mídias.

De qualquer forma as redes produzem uma diversidade imensa de "sujeitos" discursivos pela simples interação homem-máquina. O espaço social ocupado pelo sujeito contemporâneo é influenciado pela imensa quantidade de informações veiculadas pelas mídias digitais, que faz circular com uma velocidade espetacular valores e padrões de comportamento que são reproduzidos sistematicamente pelos sujeitos. Novos atores sociais utilizam as ferramentas computacionais como canal de expressão de suas opiniões, sejam elas políticas, econômicas, religiosas, afetivas ou estéticas.

Segundo Maria Rita Kehl (2003), o corpo que não se insere na marcação social do tempo fica fora da história, ou seja, o corpo ou sujeito produzido pela influência do ciberespaço é marcado pelo assujeitamento ideológico, no qual, seus próprios afetos e desejos são instrumentalizados ou submetidos a uma construção discursiva que só tem sentido e significado quando inserido no discurso social de seu tempo.

Afirma Kehl (2003, p. 245-246) a esse respeito,

[...] se os corpos não existem fora da linguagem, as práticas da linguagem determinam a aparência, a expressividade e até mesmo a saúde dos corpos. Observem o que se passou, de uns vinte anos para cá, com os corpos dos jovens pobres no Brasil. São corpos muito diferentes do que foram os corpos de seus pais e de seus avós, tão pobres como eles, tão desamparados como eles [...]. No entanto,, de duas ou três décadas para cá, os corpos dos jovens pobres brasileiros não se distinguem, a não ser pela cor da pele, dos corpos dos jovens da elite. Não são mais corpos humilhados, cabisbaixos, submetidos. [...] os jovens pobres de hoje ostentam corpos altivos, belos, erotizados.

Quais são as marcações discursivas que determinam essa mudança significativa nos

técnicas de produção graças as quais podemos produzir, transformar e manipular objetos; 2) as técnicas de sistemas de signos, que permitem a utilização de signos, de sentidos, de símbolos ou de significação; 3) as técnicas de poder, que determinam a conduta dos indivíduos, submetendo-os a certos fins ou à dominação, objetivando o sujeito; 4) as técnicas de si, que permitem aos indivíduos efetuarem, sozinhos ou com a ajuda de outros, um certo número de operações sobre seus corpos e suas almas, seus pensamentos, suas condutas, seus modos de ser; de transformarem-se a fim de atender um certo estado de felicidade, de pureza, de sabedoria, de perfeição ou de imortalidade. 
efeitos de sentido sobre os corpos dos jovens pobres brasileiros? Parece que as mídias em geral e em particular as redes sociais possuem grande influência nessa mudança, pois funcionam como catalisadores de democratização dos padrões de comportamento e de uso que o discurso capitalista traz para a sociedade, por meio de valores sedimentados no conceito do "ter", na "posse" e no domínio do capital.

Como afirma Kehl (2003), em parte essa recente erotização de todos os corpos é resultado da produção de imagens, efeito da cultura de massa, da publicidade, da televisão e da internet, que apela, sim, a que todos os corpos sejam belos, sensuais, sadios, desejáveis. Portanto, a inclusão dos jovens pobres no circuito de erotização e desejo da sociedade capitalista é efeito de discurso.

Não é de hoje que o culto ao corpo e às proporções perfeitas ocupa o centro dos investimentos estéticos, pois ter um corpo magro, hipertrofiado e bem definido é um bom cartão de ingresso aos espaços mais seletos. Nas redes sociais isto não seria diferente, a ousadia aliada ao desejo de aceitação pelo grupo leva muitos usuários a verdadeiros contorcionismos visuais na publicação de seus corpos. Postagens que margeiam desde a sensualidade discreta e comedida até o erotismo explícito e sugestivo, às vezes, explicito demais às próprias normas de publicações impostas pelas redes sociais, provocando alvoroço em meio ao burburinho constante do mundo virtual. Estas postagens convertem os corpos em corpos de transição, ao serem avaliados, classificados e ressignificados pelos usuários. Aqui o corpo erotizado e estilizado do jovem pobre se equipara ao corpo do jovem rico, pois ambos adentram ao mesmo campo de imanência, desterritorializados e comungando a mesma ordem discursiva, ou seja, corpo como produto.

O perfil do facebook produzido por um adolescente na periferia será recheado de discursos que evidenciarão características e valores sociais que serão observados e compartilhados por outros usuários que ao se identificarem com tais atributos valorativos irão necessariamente inserir e aceitar este avatar ou simulacro de personalidade na aldeia digital. $\mathrm{O}$ perfil de outro adolescente que pertença à classe média alta não se diferenciará em relação à circulação da mesma ordem discursiva portadora dos mesmos valores. O que há em comum? Roupas, sapatos, músicas, locais de lazer etc. Mesmo que os objetos de marca sejam falsificados ou pirateados ou até reclassificados como de segunda linha (até isto as Novas Tecnologias digitais facilitaram), se encontram ao alcance de quase todos os usuários, estejam nos bairros mais nobres ou nas periferias. $\mathrm{O}$ apoderamento de tais oportunidades chega a todos pelas mídias e possuí-las veiculando-as nas redes sociais por meio de perfis cria um cenário de suposta igualdade de oportunidades. 
O corpo virtual do adolescente pobre enquanto construção discursiva se iguala e se identifica com qualquer outro que compartilhe os mesmos efeitos de sentido. Corpo nivelado discursivamente, ressignificado pelos usuários que o insere na ordem discursiva. Este processo cria cenários que diminuem visualmente a diferença de classes sociais, mesmo que na vida real tais sujeitos ocupem espaços sociais bem definidos com verdadeiros hiatos de separação.

Um perfil nas redes sociais para ser notado deve invocar e despertar fascínio e atenção. Há uma racionalização na escolha das melhores fotos, na autodescrição daquilo que se deseja que os outros saibam e pensem. O perfil torna-se o palco ou cenário de um grande teatro onde se monta um espetáculo do "eu" construído intencionalmente como um apêndice do eu real, uma personalidade virtual com corpo, atributos e valores pasteurizados. Este perfil deve ser atrativo, com o risco de cair no esquecimento ou ostracismo virtual; para evitar tal risco, o usuário deve utilizar a criatividade, ostentando cenários que sejam sonho de consumo, publicando fotos e vídeos em lugares perfeitos com pessoas fisicamente atrativas. O sucesso de seu perfil se dá pela quantidade de likes que recebe o que demonstra seu grau de aceitação e popularidade na comunidade virtual, e para isto a novidade torna-se uma necessidade constante.

Tais evidências demonstram a influência das mídias na percepção de si, como um sujeito pertencente a um imaginário coletivo que se repete em vários sujeitos que comungam da mesma opinião, e que encontram no ciberespaço o domínio para fazer circular seus discursos e suas ideias.

O fato é que as redes sociais hoje são cada vez mais utilizadas na circulação de discursos variados, com destaque àqueles veiculados ao corpo, aos afetos e desejos. Cada vez mais, busca-se na rede receitas para o êxito sexual, o sucesso em relacionamentos ou até mesmo nas formas do corpo magro perfeito que atenda os padrões sociais.

A revista Veja de 06 de Novembro de 2013, trouxe como tema de capa "A estética do risco", que entre outras questões discutiu o uso da internet por personalidades da cultura da magreza na veiculação de suas medidas e na comparação dos padrões de magreza com outras pessoas.

O jornalista Alvaro Leme (2003, p. 86) que assina a matéria escreve,

[...] a internet, mais exatamente o serviço de troca de fotos pelo celular, o Instagram, é o ponto de encontro das supermagras. É ali que elas, num nicho chamado informalmente de Instafit, comparam suas medidas e se gabam de ter menos gordura do que as outras. Quem puxa a fila são as carioca Carol 
Buffara, 28 anos (mais de 200.000 seguidores), e as baianas Gabriela Pugliesi, de 28 anos (400.000 seguidores). Elas são as musas da magreza musculosa que elevam o ideal de beleza esquálida a um novo ainda mais ousado patamar.

Ao levar em conta o número de pessoas, citado por Leme, que seguem essas personalidades na internet, fica claro o poder de persuasão e convencimento que o ciberespaço exerce sobre o comportamento e os desejos. A necessidade de se enquadrar nos padrões estéticos almejados pela maioria muda as relações de afetos ao converter as redes digitais em espaços de produção de sentido.

Por conta disso, não é raro encontrar usuários com dois perfis ou mais, cada um destinado a públicos específicos e com interesses bem particularizados. É comum a presença de perfis fakes (falsos) o que demonstra as estratégias linguísticas utilizadas para criar um sujeito cognitivo específico, que faça circular um determinado tipo de produção de sentido em territórios livres, onde diferentes sujeitos circulam margeando interesses e desejos comuns.

Para Rolnick (1995), atualmente o sujeito está exposto tanto a uma desestabilização e fragmentação exacerbada da personalidade quando lançada nas redes, quanto a um apelo pela manutenção das antigas referências identitárias. Diante desse quadro, o sujeito deve produzir um perfil maleável que lhe permita transitar entre os diferentes apelos contemporâneos. Sendo os sites de relacionamentos espaços de grande circulação de sujeitos com desejos e ampla emergência afetiva, os perfis dos usuários acompanham o transcurso da fluidez e efemeridade da própria dinâmica do site. Tal análise leva à constatação de que tal característica de maleabilidade do sujeito nas redes digitais se confunde com a fragmentação da identidade do próprio homem na contemporaneidade.

Apesar desses limites que foram constatados, a análise realizada em alguns sites de relacionamento como Tinder, Badoo e Happn constata que autodescrição possibilita uma maior apreensão do conceito de si produzida discursivamente por meio da produção de perfis. A apresentação de si realizada por recursos linguísticos e psicológicos converte essas plataformas computacionais em vitrine de sujeitos aptos a relacionamento num cardápio de supostos candidatos.

A produção de novas subjetividades no ciberespaço é amplamente analisada por Turkle (1997), para quem a internet tem contribuído para a diluição da identidade e a produção de uma multiplicidade de sujeitos. Para essa autora, “[...] os bate-papos virtuais permitem ao sujeito desmembrar sua identidade em várias, de forma a permitir-lhe vivenciar uma nova identidade, ou outras novas identidades de acordo com sua fantasia e desejo." (TURKLE, 1997, p. 98). 
Como se é levado a interagir com um site de relacionamento na internet? Como acessar esse cardápio de supostos parceiros virtuais? Para ter acesso ao vasto conjunto de parceiros potenciais disponíveis é necessário efetuar um cadastro minucioso do candidato. $\mathrm{O}$ preenchimento do chamado "perfil" pessoal é o que possibilita ao site, em posse dos dados descritos pelo usuário, cruzar suas informações com o banco de dados e direcioná-lo ao perfil de outros candidatos em potencial, que se assemelham aos interesses informados.

Segundo Illouz (2011, p. 111) o perfil criado pelo usuário se torna, “[...] a versão computacional de quem é você. E é esse perfil psicológico que será cortejado com as parceiras(os) potencialmente compatíveis."

Para Illouz (2011), nos sites de relacionamento, o indivíduo é simultaneamente solicitado a se descrever, evocar e refinar, na fantasia os seus ideais (de amor, parceiro e estilo de vida). A identidade virtual é construída mediante sua decomposição em categorias discursivas e distintas de gostos, opiniões, personalidade e temperamento, portanto, é levada a conhecer um outro com base na ideia e na ideologia da compatibilidade psicológica e afetiva. Ou seja, é produzido um sujeito psíquico mediante a linguagem autodescritiva.

\section{Considerações finais}

$\mathrm{O}$ advento das redes digitais parece diminuir as fronteiras do corpo em relação à mente. Sendo as maquinarias computacionais espaço de grande circulação de informações, cria variados campos de enunciação com possibilidades de grande circulação de discursos que são produzidos por gestos de leitura e interpretação. As redes sociais produzem por esses elementos externos conjuntos de sujeitos que ocupam espaços específicos para determinado tipo de demanda.

O fato é que se torna impossível na atualidade pensar as atividades humanas, sejam elas privadas ou profissionais desvinculadas do uso das maquinarias computacionais. Raras vezes na história o corpo foi tão exposto como na atualidade pelas redes sociais Ao analisar a interação homem-máquina fica claro que os indivíduos cada vez mais incorporam à sua intimidade os serviços e interações oferecidos por uma diversidade de plataformas no ciberespaço. As expressões da sexualidade são algumas dessas características de mudança de comportamento percebidas.

As enunciações produzidas na relação homem-máquina determinam nas novas gerações (também chamada de geração Z) modalidades de subjetividade bem particulares, no qual, a própria personalidade e a organização cognitiva podem manifestar determinados tipos 
de acontecimentos.

Por meio de aplicativos, sites de relacionamento e redes sociais, uma parcela crescente de pessoas está abdicando das relações na vida real, para adentrar o mundo virtual e por meio de avatares ou perfis criados na rede, se relacionar com uma diversidade maior de sujeitos. A apresentação de si nos sites de relacionamento, em especial o Tinder, Badoo e Happn que foram escolhidos como objeto de análise desse artigo, criada por usuários desses serviços possibilita a produção e circulação de subjetividades variadas que atendem às necessidades e interesses específicos. Por conta disso, a escrita sobre si demanda um determinado tipo de enunciação com seus efeitos de sentido específicos. A posição ocupada pelo sujeito é trilhada pela escrita de si, é por essa posição que ocupa que faz circular pela prática discursiva o tipo de produção que deseja.

\section{REFERÊNCIAS}

BAUMAN, Z. Amor líquido: sobre a fragilidade dos laços humanos. Rio de Janeiro: Zahar, 2004.

FOUCAULT, M. História da sexualidade: o uso dos prazeres. Rio de Janeiro: Graal, 1998.

ILLOUZ, E. O amor nos tempos do capitalismo. Rio de Janeiro: Zahar, 2011.

KEHL, M. R. As máquinas falantes. In: NOVAES, A. O homem máquina: a ciência manipula o corpo. São Paulo: Companhia das Letras, 2003. p.123-145.

LEME, A. A estética do risco. Veja, São Paulo, ed. 2346, n.46, p.84-88, 2013.

ROLNICK, S. O mal-estar na diferença. Anuário Brasileiro de Psicanálise, Rio de Janeiro, n.3, p.97-103, 1995.

TURKLE, S. A vida no ecrã: a identidade na era da internet. Tradução de Marco Antonio Esteves da Rocha. Lisboa: Relógio d'Água, 1997.

\section{Como referenciar este artigo}

SANTOS, Fausi dos.; RIBEIRO, Paulo Rennes Marçal. Privacidade em tempos de internet: comportamento e discursivização de si entre usuários no ambiente virtual. Doxa: Rev. Bras. Psicol. Educ., Araraquara, v.19, n.2, p. 258-267, jul./dez. 2017. e-ISSN: 2594-8385. 